\title{
Event-related theta power during lexical-semantic retrieval and decision conflict is modulated by alcohol intoxication: anatomically constrained MEG
}

\author{
Ksenija Marinkovic $^{1}{ }^{*}$, Burke Q. Rosen ${ }^{1}$, Brendan Cox $^{2}$ and Sanja Kovacevic ${ }^{1}$ \\ 1 Department of Radiology, University of California, San Diego, CA, USA \\ ${ }^{2}$ Martinos Center for Biomedical Imaging, Massachusetts General Hospital and Harvard Medical School, Boston, MA, USA
}

Edited by:

Marcela Pena, Catholic University of

Chile, Chile

\section{Reviewed by:}

Benjamin Dering, Salk Institute for

Biological Studies, USA

Carolyn McGettigan, University

College London, UK

\section{*Correspondence:}

Ksenija Marinkovic, Department of Radiology, University of California, San Diego, 9500 Gilman Drive 0841, La Jolla, CA 92093-0841, USA.

e-mail:xenia@ucsd.edu
Language processing is commonly characterized by an event-related increase in theta power $(4-7 \mathrm{~Hz})$ in scalp EEG. Oscillatory brain dynamics underlying alcohol's effects on language are poorly understood despite impairments on verbal tasks. To investigate how moderate alcohol intoxication modulates event-related theta activity during visual word processing, healthy social drinkers ( $N=22,11$ females) participated in both alcohol $(0.6 \mathrm{~g} / \mathrm{kg}$ ethanol for men, $0.55 \mathrm{~g} / \mathrm{kg}$ for women) and placebo conditions in a counterbalanced design. They performed a double-duty lexical decision task as they detected real words among non-words. An additional requirement to respond to all real words that also referred to animals induced response conflict. High density whole-head MEG signals and midline scalp EEG data were decomposed for each trial with Morlet wavelets. Each person's reconstructed cortical surface was used to constrain noise-normalized distributed minimum norm inverse solutions for theta frequencies. Alcohol intoxication increased reaction time and marginally affected accuracy. The overall spatio-temporal pattern is consistent with the leftlateralized fronto-temporal activation observed in language studies applying time-domain analysis. Event-related theta power was sensitive to the two functions manipulated by the task. First, theta estimated to the left-lateralized fronto-temporal areas reflected lexicalsemantic retrieval, indicating that this measure is well suited for investigating the neural basis of language functions. While alcohol attenuated theta power overall, it was particularly deleterious to semantic retrieval since it reduced theta to real words but not pseudowords. Second, a highly overlapping prefrontal network comprising lateral prefrontal and anterior cingulate cortex was sensitive to decision conflict and was also affected by intoxication, in agreement with previous studies indicating that executive functions are especially vulnerable to alcohol intoxication.

Keywords: lexical decision, pseudowords, lexical-semantic retrieval, conflict processing, inferior frontal, anterior cingulate, temporal cortex

\section{INTRODUCTION}

Long-term alcohol abuse and dependence result in neurobehavioral decline that is reflected in diverse changes in the brain and behavior as alcohol's effects reach across cognitive, emotional, psychomotor, and social abilities (Oscar-Berman and Marinkovic, 2007). Neuropsychological investigations indicate deficits in memory, visuospatial, and motor functions (Oscar-Berman and Hutner, 1993; Nixon et al., 1995; Oscar-Berman, 2000; Sullivan et al., 2000), but executive control skills are particularly impaired (Johnson-Greene et al., 1997; Lyvers, 2000; Moselhy et al., 2001). Some studies suggest relative sparing of verbal skills compared to more pronounced deficits on non-verbal tasks (Parsons, 1987; Oscar-Berman and Schendan, 2000; Moselhy et al., 2001). However, evidence obtained with event-related potentials (ERPs) indicates deficits in semantic processing in individuals with alcohol dependence (Nixon et al., 2002; Roopesh et al., 2010). A negative deflection peaking at $\sim 400 \mathrm{~ms}$ (N400) is evoked by potentially meaningful material and has been interpreted as an attempt to access and integrate a semantic representation into a current context (Halgren, 1990; Brown and Hagoort, 1993; Holcomb, 1993; Friederici, 1997; Kutas and Federmeier, 2000). Using a sentence paradigm, Nixon et al. (2002) reported a reduced N400 to the incongruent sentence-terminal words in abstinent alcoholics. Roopesh et al. (2010) recorded ERPs from abstinent alcohol dependent individuals and compared the N400 evoked by semantically primed and unprimed words. The priming-induced attenuation of the N400 was much smaller in alcohol dependent participants compared to controls (Roopesh et al., 2010). Similar deficiency in semantic processing was observed in young individuals at risk for developing alcoholism (Roopesh et al., 2009). Although more studies are needed, this evidence indicates that the deficits in semantic access and integration in chronic alcoholic cohorts may be a consequence of excessive drinking, with possible contributions from dispositional factors. 
Behavioral studies administering an acute alcohol challenge to healthy participants have reported detrimental effects on verbal learning and memory. Intoxication impairs free recall of verbal material (Maylor et al., 1990; Mungas et al., 1994), with semantic memory access being particularly affected (Maylor et al., 1990; Acheson et al., 1998). While explicit verbal memory is adversely affected by intoxication, implicit memory remains unimpaired (Lister et al., 1991; Tracy and Bates, 1999; Ray et al., 2004; Garfinkel et al., 2006). Neuroimaging studies of acute alcohol effects on language are scarce. A study using Single Photon Emission Computed Tomography (SPECT) showed that moderate intoxication reduces regional cerebral blood flow in the left dorsolateral prefrontal cortex, as well as performance during a verbal fluency test (Wendt and Risberg, 2001). Our previous work using ERPs has shown that moderately low alcohol intoxication affects visual word processing at both early and late stages during word recognition (Marinkovic et al., 2004b). More specifically, the left-dominant N180 was attenuated by alcohol, suggesting deficient feature identification and prelexical pattern analysis. Conversely, the larger N450 under intoxication indicates increased difficulty in attempting to access semantic representations. While this evidence clearly suggests that acute intoxication affects visual word processing, the extant research in the semantic domain is exceedingly limited in scope and methodology and necessitates further investigation. Other lines of research on acute alcohol effects on cognition indicate that alcohol is particularly deleterious under the conditions demanding increased cognitive control, such as divided attention (Koelega, 1995), increased memory load (Paulus et al., 2006), and conflicting or ambiguous task demands (Marinkovic and Azma, 2010; Marinkovic et al., 2012).

The present study was designed to integrate and expand on these findings in several ways. First, in order to investigate whether the effects of alcohol were specific to lexical-semantic processing, we employed a lexical decision task in which participants were asked to detect visually presented real words among non-words. Second, the lexical decision task was embedded in a double-duty paradigm that included an additional requirement to detect all real words that also referred to animals. By manipulating conflicting demands in the context of lexical-semantic retrieval, this task modification allowed us to examine the effects of acute intoxication on both language and executive functions. Third, the whole-head magnetoencephalography (MEG) signal was analyzed with a Time-Frequency (TF) method, providing an insight into the oscillatory dynamics of the distributed network subserving visual word processing. In an effort to examine where the conflict- and beverage-specific brain oscillatory changes are occurring and to gain insight into the temporal sequence ("when") of the involved neural components, we have employed a multimodal neuroimaging methodology. The anatomically constrained MEG (aMEG) analysis stream combines distributed source modeling of the MEG signal with high-resolution structural MRI, yielding "brain movies" that map spectral power estimates across time (Dale and Sereno, 1993; Dale et al., 2000; Lin et al., 2004). Fourth, the oscillations in theta $(4-7 \mathrm{~Hz})$ frequency band are particularly sensitive to the effects of chronic alcohol use and risk status as shown by reduced event-related theta power in executive tasks (Kamarajan et al., 2004, 2006; Rangaswamy et al., 2007; Andrew and Fein, 2010). Furthermore, given their high heritability and the genetic links of theta oscillations with alcohol dependence, changes in theta band have been suggested as an endophenotype of vulnerability to alcoholism (Porjesz et al., 2005; Begleiter and Porjesz, 2006). In light of this evidence, it is surprising to note that research on the acute effects of alcohol on theta oscillations has been exceedingly limited (Krause et al., 2002). Fifth, previous EEG studies using cognitive tasks have observed increased theta power during the engagement of executive functions (McEvoy et al., 2001; Jensen and Tesche, 2002; Brier et al., 2010) particularly in prefrontal areas (Kovacevic et al., submitted). Consistent with the notion that memory processes are reflected in theta oscillations (Klimesch, 1999; Klimesch et al., 2001), language studies have shown that the theta band is sensitive to the lexical-semantic retrieval (Bastiaansen et al., 2005, 2008).

Taken together, the main goal of this study was to examine the effects of moderate alcohol intoxication on event-related theta power during a dual-task visual word paradigm that manipulated semantic and executive dimensions. Healthy social drinkers served as their own controls by participating in both alcohol and placebo conditions in a counterbalanced design.

\section{MATERIALS AND METHODS SUBJECTS}

Twenty-two adult volunteers ( 11 men, mean \pm SD age $=24.5 \pm$ 4.3 years) completed all sessions of the experiment. These were all healthy, right-handed non-smoking native English speakers who reported no medical, alcohol- or drug-related problems, and were medication-free at the time of the study. None reported previous head injury or had any MRI contraindications. The participants were light social drinkers and reported drinking alcohol $2.1 \pm 1.1$ times per week and in low-to-moderate amounts $(2.7 \pm 0.9$ drinks per occasion) adapted Alcohol Use Questionnaire (Cahalan et al., 1969). The quantity or frequency of drinking did not differ between genders. No alcoholism-related symptoms were detected among the participants with Short Michigan Alcoholism Screening Test (SMAST, Selzer et al., 1975) and they reported no family history of alcohol or drug abuse (i.e., first or second degree relatives). Written informed consent approved by the Human Research Committee at Massachusetts General Hospital and the Partners Healthcare Network was obtained from all subjects before participation. Participants were compensated for taking part in the study. Four additional subjects completed the study, but their data were discarded due to noisy signal in one of the two experimental sessions (three subjects) and difficulties with staying awake (one subject).

\section{EXPERIMENTAL DESIGN AND PROCEDURE}

All subjects completed three MEG recording sessions and also underwent a structural MRI scan. First, they took part in an introductory session in which they provided detailed information on their medical history, family history of alcoholism, quantity and frequency of alcohol use (modified from Cahalan et al., 1969), severity of their alcoholism-related symptoms (SMAST, Selzer, 1971), and handedness (Oldfield, 1971). In addition, the following questionnaires were used in order to obtain a comprehensive dispositional profile of each subject, with particular respect 
to disinhibitory, novelty seeking and socialization traits: Childhood Hyperactivity Questionnaire (HK/MBD, Tarter et al., 1977); Eysenck Personality Questionnaire (EPQ, Eysenck and Eysenck, 1975); Socialization Scale of the California Psychological Inventory (Gough, 1994); Zuckerman Sensation Seeking Scale (Zuckerman, 1971). Furthermore, during this session subjects were familiarized with the experimental procedure and laboratory setting by participating in a brief MEG recording, with the purpose of reducing the potential effects of situation-induced arousal (Maltzman and Marinkovic, 1996).

Subsequently, participants took part in both placebo and alcohol sessions that were $17 \pm 13$ days apart on average, in a counterbalanced order, so that alcohol was presented in the first session for half the sample and in the second session for the other half. The within-subject design minimized influence of individual differences in neuroanatomy and alcohol metabolism yielding reduced error variance and increased statistical power. Subjects were asked to abstain from food for $3 \mathrm{~h}$ and from alcohol for at least $48 \mathrm{~h}$ prior to each experimental session. To confirm that they were not pregnant, women were given a urine test prior to each scanning session. Breath alcohol concentration (BrAC) was measured with a breathalyzer (Draeger, Inc.) upon arrival and throughout the session, except when subjects were inside the recording chamber. Subjects rated their moods and feelings with the Biphasic Alcohol Effects Scale (BAES, Martin et al., 1993) prior to drinking (at baseline), immediately before and after the task. In the alcohol session, the beverage contained $0.60 \mathrm{~g} / \mathrm{kg}$ of ethanol for men and $0.55 \mathrm{~g} / \mathrm{kg}$ for women and was administered as a cocktail containing $20 \% \mathrm{v} / \mathrm{v}$ of vodka (Grey Goose, Bacardi) mixed with orange juice. The same volume of orange juice was administered in the placebo session (Marinkovic et al., 2012). The task was administered $38 \pm 9$ min after the beverage was consumed. It was performed at peak BrAC levels, as the average BrAC levels were $0.044 \pm 0.012 \%$ before and $0.044 \pm 0.011 \%$ after the task. At the end of each session the participants were asked to rate perceived task difficulty, content of the imbibed beverage, their confidence of that determination, and how intoxicated they felt on a 1-5 Likert scale. They were asked to estimate how many alcoholic drinks were contained in the beverage starting from 0 with 0.5 drink increments. After each session, subjects were provided transportation to their homes. High-resolution structural MRI scans were also obtained from all participants in a separate session.

\section{TASK}

The double-duty lexical decision task required subjects to respond to visually presented real, standard words (SW) with their right index finger and to imperative words (animals, AN) with the left index finger, while withholding them to all non-words. The non-words were of two types: pseudowords (PW) that were orthographically and phonologically legal letter strings with no meaning, such as "poman," and non-pronounceable non-words (NW), comprised of consonants such as "dscrt." Participants were instructed to respond as quickly as possible, without losing accuracy. Two different stimulus lists were created and were administered in a counterbalanced manner across beverage conditions and subjects. 110 stimuli for each condition were randomly presented with the Presentation software package (Neurobehavioral
Systems) in white letters on the black background for $300 \mathrm{~ms}$ preceded and followed by a fixation string $(\mathrm{xxxx})$ with a total trial length of $2.5 \mathrm{~s}$. Short breaks were given every $\sim 4 \mathrm{~min}$. All stimuli categories were matched for the word length on average, AN: $6.2 \pm 1.7$ letters; SW: $6.3 \pm 1.6$; PW: $6.2 \pm 1.7$; NW: $6.0 \pm 1.3$. The number of syllables in the AN and SW conditions were also matched at $2.0 \pm 0.7$, and $2.1 \pm 0.8$ respectively. Finally, all meaningful words had low frequency of occurrence and were matched across the two conditions, AN: $5.5 \pm 8.9$; SW: $4.3 \pm 2.4$ per million (Francis and Kucera, 1982), although not all the animals were found in this published database. In addition to the lexicalsemantic and imperative characteristics, perceptual novelty (larger font) and repetition of words, and pseudowords were manipulated. However, because the results of these manipulations did not interact with the effects of beverage, they will not be discussed further here. Similarly, NW served as non-response fillers and the results are not presented here. Behavioral results are shown in Figure 1.

\section{DATA ACQUISITION AND ANALYSIS MRI}

A 3T Siemens Trio whole-body scanner (Siemens, Erlangen) was used to acquire structural MRI images. For each subject, two highresolution 3D MP-RAGE T1-weighted sequences that optimize contrast for a range of tissue properties were obtained with the following parameters: $\mathrm{TR}=2.53 \mathrm{~s}, \mathrm{TE}=3.25 \mathrm{~ms}$, flip angle $=7^{\circ}$, FOV $=256,128$ sagittal slices, $1.33 \mathrm{~mm}$ thickness, in-plane resolution $1 \mathrm{~mm} \times 1 \mathrm{~mm}$. These images were used to reconstruct each person's cortical surface (Dale et al., 1999; Fischl et al., 1999a). Inner skull surface was derived from the segmented MRI data and used for a boundary element model of the volume conductor in the forward calculations. The gray-white matter surface was morphed into average space (Fischl et al., 1999b) and decimated, thereby defining the solution space with 5124 free-rotating dipoles spaced $\sim 7 \mathrm{~mm}$.

\section{Magnetoencephalography}

High-density MEG signals were recorded from 204 channels comprising 102 pairs of planar gradiometers, with a whole-head Vectorview instrument (Elekta-Neuromag) in a magnetically and electrically shielded room. The signals were recorded continuously with $601 \mathrm{~Hz}$ sampling rate and minimal filtering $(0.5-100 \mathrm{~Hz})$. The




main fiduciary points such as the nasion and preauricular points, the position of magnetic coils attached to the skull, and a large array of random points spread across the scalp were digitized with 3Space Isotrak II system for subsequent precise co-registration with structural MRI images.

Data were analyzed with custom-made Matlab routines, in addition to relying on publicly available packages including FieldTrip (Oostenveld et al., 2011) and EEGLAB (Delorme and Makeig, 2004). Epochs extending -800 to $1250 \mathrm{~ms}$ relative to stimulus onset were extracted and detrended. Longer epochs were selected to prevent contamination of time window of interest $(-300$ to $800 \mathrm{~ms}$ ) with edge artifacts during wavelet analysis. A combination of automatic threshold rejection, careful visual inspection, and independent component analysis (Delorme and Makeig, 2004) was used to remove epochs with eye-blink and other artifacts. In order to eliminate potential statistical bias, the tallies of artifact-free correct trials were equalized across beverage and task conditions by removing superfluous trials at random.

Complex wavelet power spectra were calculated for each epoch by convolving them with complex Morlet wavelets (Lachaux et al., $1999)$ in $1 \mathrm{~Hz}$ increments from 4 to $7 \mathrm{~Hz}$, with a constant time resolution $\left(\sigma_{t}\right)$ of $80 \mathrm{~ms}$ and frequency resolution $\left(\sigma_{f}\right)$ of $2 \mathrm{~Hz}$. Wavelet length was set to constant $500 \mathrm{~ms}$ and varied from two to four cycles in the specified frequency range. Complex power spectra were trimmed down to -300 to $800 \mathrm{~ms}$ time window, excluding the data points potentially affected by edge artifacts, and downsampled, resulting in $6.7 \mathrm{~ms}$ temporal sampling rate. Estimated source power constrained to cortical surface was calculated based on the spectral dynamic statistical parametric mapping approach (Lin et al., 2004), by applying cortically constrained minimum norm estimation procedure (Dale et al., 2000) to the complex wavelet power spectrum. To prevent biasing the inverse solution against spontaneous brain oscillations, the noise covariance used for inverse calculation was estimated from the empty room data pooled across recording sessions and band-pass filtered between 3 and $50 \mathrm{~Hz}$. A signal-to-noise ratio (SNR) of 5 (Lin et al., 2004) was used for scaling of the noise covariance in calculation of the inverse operator. An identity matrix was used for the noise-sensitivity normalization of the source-space solution. The noise-sensitivity normalized estimates of total source power were obtained for each frequency at each location on the cortical surface. For each subject, a map of total theta source power was calculated by averaging across frequencies and trials. Total event-related theta power estimates were then baseline corrected by subtracting the mean theta source power estimate in the $300 \mathrm{~ms}$ prestimulus period. Group average maps of baseline-corrected total theta power are shown in Figures 2-4.

To examine possible interactions of the factors of beverage and task conditions, and to ascertain the statistical reliability of the observed effects, region-of-interest (ROI) analysis was conducted on the event-related changes in total theta power. Unbiased ROIs comprised dipole locations along cortical surface with most notable source power and were selected based on the overall group average across all subjects, task and beverage conditions. The same ROIs were used for all subjects in a manner blind to their individual activations by applying an automatic spherical morphing procedure (Fischl et al., 1999b). For each subject, task condition and beverage, theta estimates were averaged across all cortical points comprised in that ROI and these values were entered into ANOVA. The ROIs encompassed the left-lateralized fronto-temporal network associated with language and cognitive/executive operations (Figures 2-4), as well as comparable regions on the right. ROIs included the lateral occipital area (Occ), lateral temporal (LT) cortex, anteroventral inferior prefrontal cortex (aIPF) bordering on insula, posterolateral inferior prefrontal cortex (pIPF), motor cortex centered on hand area (Mot), and the anterior cingulate cortex (ACC) bilaterally.

For both behavioral and imaging data the repeated measures ANOVAs (SPSS for Windows, SPSS Inc) were carried out with the factors of beverage (alcohol, placebo), and condition (SW, PW, AN). The ANOVAs were performed for each ROI event-related theta power averaged over time points in four time windows, T1 (110-160 ms), T2 (170-320 ms), T3 (370-520 ms), T4 (600$750 \mathrm{~ms}$; Figure 2). Effects of lexical-semantic retrieval on theta power were examined by direct comparisons between the activity estimates to SW and PW, word-like, pronounceable letter strings with no meaning (Figure 3; Table 1). Conversely, a direct comparison between the SW and AN provided insight into the effects of decision conflict (Figure 4; Table 1). In addition, uncorrected baseline power estimates were submitted to the same analysis in order to examine potential effects of beverage and task condition for the -300 to $0 \mathrm{~ms}$ time window. In an effort to examine possible effects of session order, we also included the order effect in the statistical model for all dependent variables. However, no significant effects of session order were observed.

\section{EEG}

EEG signal was measured at $\mathrm{Fz}$ and $\mathrm{Cz}$ sites simultaneously with the MEG signal in order to provide a complementary measure of the effects of alcohol on event-related theta power and to relate our findings to previous EEG studies. The signal was referred to an electrode placed on the tip of the nose, whereas the right earlobe served as ground. An electrooculogram (EOG) was recorded as well, with bipolarly referred electrodes placed at the outer canthus of the left eye and just above the nasion. Electrode impedance did not exceed $5 \mathrm{k} \Omega$. Good quality complete EEG data sets were acquired from 20 participants and analyzed with the same signal-space analysis described above. Grand averages of event-related power were expressed as relative change to the prestimulus period and were calculated as follows: normalized power $N(t, f)=[P(t, f)-B(f)] / B(f)$, where $P(t, f)$ is raw total power at timepoint $t$ and frequency $f$ and $B(f)$ is mean power for frequency $f$ in the prestimulus time window. The total event-related theta power was averaged across the 450-650 ms latency window and analyzed with repeated measures ANOVA as described above.

\section{RESULTS \\ BEHAVIORAL MEASURES \\ Performance}

Performance accuracy differed as a function of stimulus type [main effect of condition, $F(2,42)=11.4, p<0.001$ ], with percent accuracy means ( \pm SD) as follows: SW: $90.9( \pm 7.1)$, AN: 83.0 $( \pm 9.4)$, and PW: $92.9 \%( \pm 12.9)$, Figure 1. Subjects responded least accurately to AN compared to both SW, $F(1,21)=21.7, p<0.001$, 




FIGURE 2 | Group average maps of baseline-corrected event-related theta source power estimates in the left hemisphere for the three conditions under placebo at different time points. The earliest activity is estimated to the occipital cortex, followed by the left lateral temporal and inferior prefrontal estimates during the processing of lexical-semantic characteristics and decision conflict. During response preparation and execution stage, theta power is estimated to the hand-centered motor area. Group average timecourses of theta source power estimates in selected regions of interest are shown on the bottom. Light-shaded vertical bars indicate the time-windows for which theta power was averaged and entered into statistical analysis as indicated at the top. Occ, occipital cortex; LT, lateral temporal; alPF, anteroventral inferior prefrontal cortex bordering on insula; pIPF, posterolateral inferior prefrontal cortex; Mot, motor cortex centered on the hand area. Please note that a different scale was used for the temporo-frontal estimates during T2 and T3 time windows in order to accommodate weaker sources during cognitive processing (Marinkovic et al., 2004a). and PW, $F(1,21)=21.1, p<0.001$. Performance accuracy was only marginally decreased by alcohol overall, $F(1,21)=3.3, p<0.09$, but beverage comparisons were not significant for any individual condition. Reaction times were significantly increased by alcohol overall as indicated by a main effect of beverage, $F(1,21)=5.438$, $p<0.05$, with means $( \pm S D)$ of $811 \pm 119 \mathrm{~ms}$ for alcohol and $777 \pm 105 \mathrm{~ms}$ for placebo. The overall response speed did not differ between SW and AN.

\section{Post-experimental questionnaire and mood ratings}

At the end of each experimental session participants rated the beverage content, the perceived level of intoxication and task difficulty on Likert scales (1-5). Participants correctly perceived the beverage content under both alcohol $(5.0 \pm 0.2)$ and placebo $(1.5 \pm 0.9)$. On the scale from 1 (not at all) to 5 (very much), participants reported feeling moderately intoxicated $(2.8 \pm 0.7)$ under alcohol, but not at all intoxicated under placebo $(1.0 \pm 0.2)$, $F(1,21)=121.7, p<0.001$. Subjects estimated that the alcoholic beverage contained $2.4 \pm 0.8$ "alcoholic drinks," a slight underestimate of the actual average amount containing 2.8 standard drinks defined as $1.5 \mathrm{fl} \mathrm{oz}$ of vodka. They also estimated that the placebo beverage contained $0.1 \pm 0.4$ "alcoholic drinks." On the scale from 1 (easy) to 5 (difficult), subjects rated the task as being moderately easy $(2.4 \pm 1.2)$ but the perceived difficulty was not influenced by beverage. These results indicate that the participants were aware of the beverage contents. Even though previous balanced placebo studies indicate that ERPs and autonomic physiological measures are influenced only by the pharmacological effects of alcohol rather than expectancy (Marinkovic et al., 2000; Marinkovic et al., 2001, 2004b), the effects of intoxication within the larger context of the social setting are likely a combination of these two influences and it needs to be taken into account.

Effects of alcohol on the momentary moods and feelings were assessed with BAES scale (Martin et al., 1993) on three occasions during each session: upon arrival (the baseline rating), prior to entering the MEG chamber, and after the experiment. Since the baseline ratings did not differ between sessions, the subsequent ratings were expressed as the relative change from the baseline. Participants reported being significantly more stimulated before than after the task, $F(1,21)=19.2, p<0.001$. 


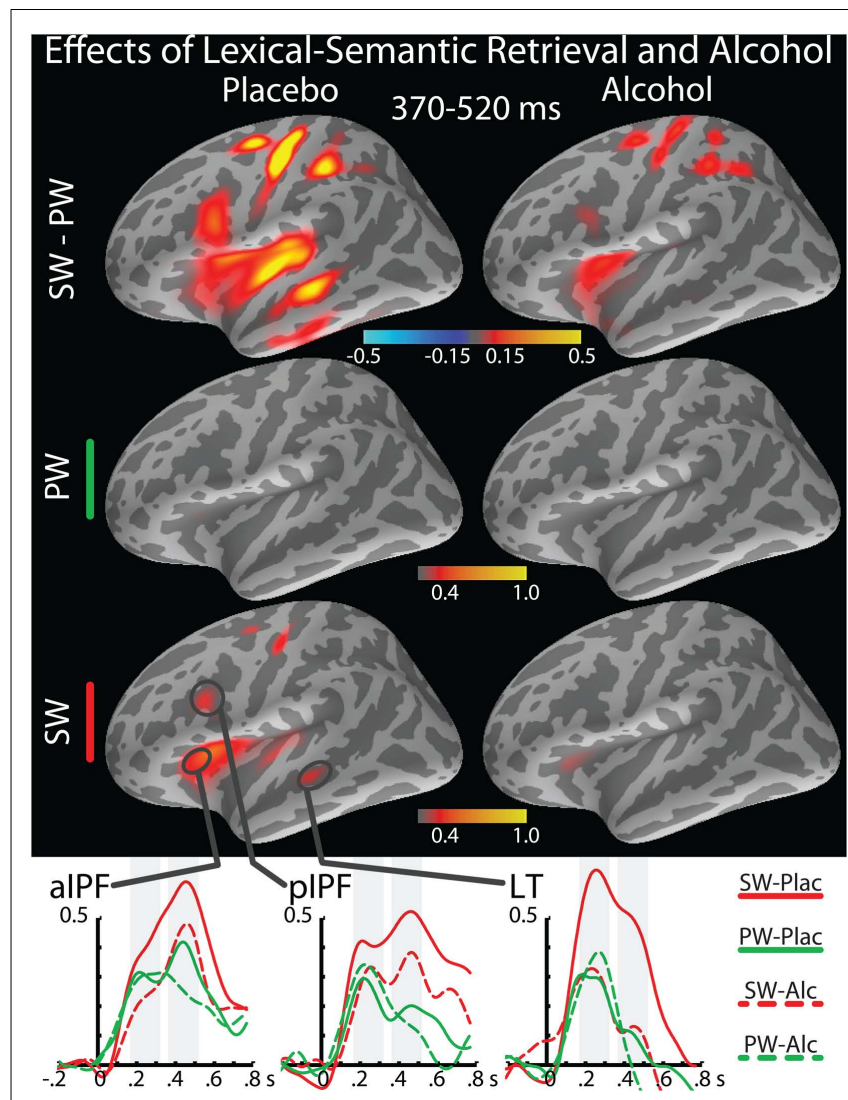

FIGURE 3 | Effects of lexical-semantic retrieval on group average maps of baseline-corrected event-related theta source power estimates in the $\mathbf{3 7 0}-\mathbf{5 2 0} \mathrm{ms}$ time-window in the left hemisphere under placebo (left column) and alcohol (right column). Maps in the top row are based on the subtraction of the meaningless PW from real words (SW). The overall averaged estimates to SW and PW are shown below the subtracted estimates. Group average timecourses of the theta estimates to SW and PW under both beverage conditions are shown at the bottom of the figure, along with the time-windows included in the statistical analysis indicated with shaded bars.

The observed interaction of condition and beverage for the estimates of "high," $F(1,21)=7.3, p<0.05$, was due to the subjects' reporting being more high under alcohol than placebo before the task, $F(1,21)=13.9, p<0.001$. The beverage effect on the "high" estimates was still marginally significant after the task, $F(1,21)=3.6, p<0.05$.

\section{MEG RESULTS}

The aMEG approach made it possible to estimate spatiotemporal stages of the event-related total theta power to words and pseudowords. The observed pattern is consistent with the left-lateralized posterior-to-anterior fronto-temporal processing stream as reported for different language tasks with time-domain aMEG analysis (Dhond et al., 2001, 2007; Halgren et al., 2002; Marinkovic et al., 2003; Marinkovic, 2004). Figure 2 depicts group average event-related theta source power estimates for the three stimulus types under placebo as they change across time. The estimates in the form of maps and timecourses for the relevant
ROIs are shown for the left hemisphere only since they were much weaker on the right overall. Wavelet-based estimates suffer from temporal smearing due to the width of the wavelet especially at lower frequencies. Nonetheless, we have observed differential modulation across time in different brain areas in agreement with the activity progression from the sensory-specific to supramodal regions during language processing (Marinkovic, 2004). The earliest activity was seen in the occipital area at $\sim 130 \mathrm{~ms}$ and it did not differ among the conditions. Lateral middle temporal area (LT) was engaged subsequently (at $\sim 250 \mathrm{~ms}$ ) and showed less theta power to PW than to other conditions. Anteroventral and posterolateral prefrontal areas showed peak theta activity at $\sim 450 \mathrm{~ms}$ and were sensitive to both, the meaning and the task-imperative characteristics of the stimuli, with the strongest source power elicited by the AN. Theta power estimates to SW were weaker than to AN, but both meaningful conditions elicited stronger theta than PW, word-like, pronounceable letter strings without meaning. In the final stage, a strong theta generator was estimated to the hand motor area after $\sim 550 \mathrm{~ms}$ in the left hemisphere, during preparation and execution of responses to SW. A very similar activity specific to $\mathrm{AN}$ was observed in the motor area in the right hemisphere.

Figures 3 and 4 depict event-related theta power maps and estimated timecourses associated with semantic and task conflict manipulations respectively as a function of alcohol intoxication. A direct comparison of theta estimates to SW and PW shows the effects of lexical-semantic retrieval under both beverage conditions (Figure 3). Similarly, Figure 4 contains theta power maps and timecourses of the AN-SW comparison showing the effects of decision conflict in the context of intoxication. Both AN and SW conditions were matched for the active responses, but the doubleduty task induced decision conflict on AN trials. Table $\mathbf{1}$ contains results of the ANOVAs of the theta power estimated to the ROIs for the MEG and EEG measured at $\mathrm{Cz}$.

\section{T1 (110-160 ms)}

Event-related theta power estimated to the left lateral occipital area was significantly decreased by alcohol, $F(1,21)=21.0, p<0.001$, but there were no effects of condition.

\section{T2 (170-320 ms)}

In this time window, the principal source of theta power was estimated to LT cortex. It was sensitive to lexical-semantic characteristics as shown by the overall SW-PW difference, $F(1,21)=5.1, p<0.05$. This difference interacted with beverage in LT, $F(1,21)=13.3, p<0.01$, as it was significant only under placebo, $F(1,21)=12.8, p<0.01$, but not under alcohol, $F(1,21)=0.3$, n.s. Alcohol selectively attenuated theta power to meaningful SW, $F(1,21)=9.5, p<0.01$, but not PW, $F(1,21)=0.4$, n.s. Very similar effects were observed in the left ACC (Table 1), with SW eliciting stronger theta power under placebo, $F(1,21)=7.8, p<0.05$, but not alcohol, $F(1,21)=2.1$, n.s. Alcohol attenuated theta estimated to the ACC overall, as indicated by the main effect of beverage, $F(1,21)=11.8, p<0.01$. The only right hemisphere contribution in this time window was alcohol-induced attenuation of theta power in the LT cortex, $F(1,21)=7.4, p<0.05$. 


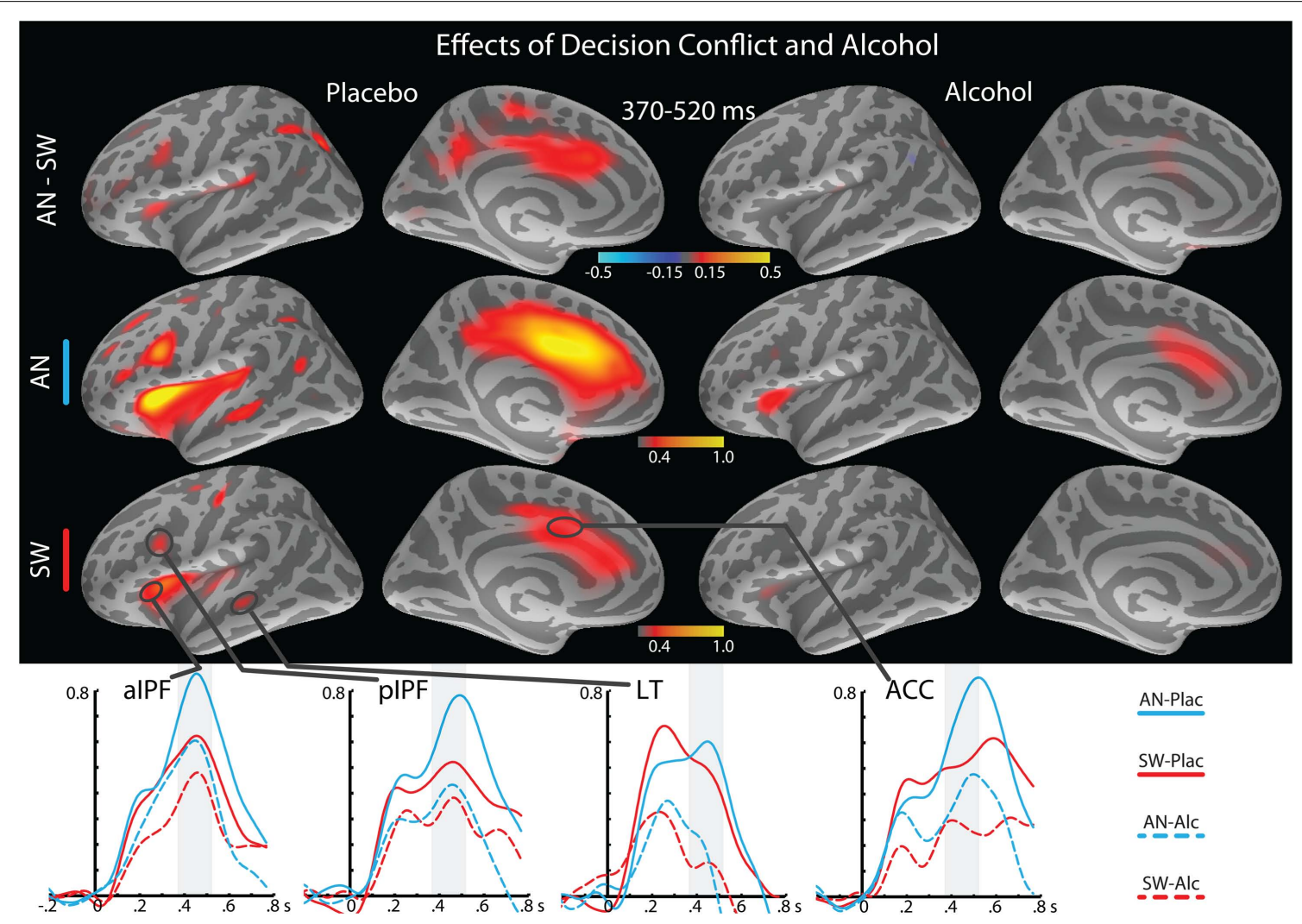

FIGURE 4 | Effects of decision conflict and alcohol intoxication on theta power estimates in the $\mathbf{3 7 0}-\mathbf{5 2 0} \mathbf{~ m s}$ time-window under placebo (left) and alcohol (right), with lateral and medial views of the left hemisphere. The top row shows the AN-SW group average subtraction, with the overall event-related theta group average estimates shown in the rows below. Group average timecourses of the theta estimates to AN and SW conditions under both alcohol and placebo are shown at the bottom. The vertical light-shaded bars denote the time-window applied to the ROI statistical analysis. ACC, anterior cingulate cortex.

\section{T3 (370-520 ms)}

The principal foci of activation in this time window were estimated to the frontal regions which, along with the continued contributions from the LT cortex underlie the two overlapping functions that appeared to be engaged by this dual-level task. First, left fronto-temporal event-related theta power was sensitive to the semantic manipulation and was attenuated by alcohol (Figure 3 ). In both lateral prefrontal and the LT region, SW elicited significantly stronger theta power than PW (Table 1). While alcohol attenuated theta power to SW, the PW remained unaffected by intoxication. Second, the prefrontal network comprising the ACC and lateral frontal areas was sensitive to decision conflict and was also affected by intoxication (Figure 4). The AN imperative words elicited significantly stronger theta power than SW particularly under placebo in both, aIPF, $F(1,21)=10.1, p<0.005$ and pIPF, $F(1,21)=10.1, p<0.005$, but not under alcohol, $F$-values were 2.7 and 0.5 respectively, neither significant. Similarly, theta power estimated to the ACC was stronger to AN than to SW under placebo, $F(1,21)=4.9, p<0.05$, but not under alcohol, $F(1,21)=2.3$, n.s. Intoxication especially attenuated theta power to AN (Table 1), indicating its effects on the executive task dimension. Whereas the theta power was stronger in the left hemisphere overall, the main effects of condition were significant in the right hemisphere across all ROIs (Table 1). This was due primarily to a stronger theta power to AN as compared to SW. The beverage effect was observed only in the LT cortex on the right, $F(1,21)=9.0, p<0.01$.

\section{T4 (600-750 ms)}

As illustrated in Figure 2, this time window captures theta power associated with motor responses to SW in the left motor area. A very similar estimate was obtained for the $\mathrm{AN}$ in the right hand area as well. Alcohol intoxication reduced event-related power to SW in the left motor area, $F(1,21)=19.2, p<0.001$, and to $\mathrm{AN}$ on the right, $F(1,21)=10.3, p<0.01$, indicating that it affects motor preparation and execution.

\section{PRESTIMULUS THETA}

Analysis of the uncorrected baseline theta power estimates detected no beverage-related differences in theta power, confirming that the observed effects of alcohol on event-related theta power were not due to systematic changes in the prestimulus period.

\section{EEG RESULTS}

Grand average timecourses of total event-related theta power under alcohol and placebo recorded at $\mathrm{Cz}$ are shown in Figure 5. 
Table 1 | Summary of statistical comparisons of the MEG event-related theta for all left (L) and right (R) ROls within T2 and T3 time windows and EEG theta within 450-650 ms latency expressed as $F$-values.

\begin{tabular}{|c|c|c|c|c|c|c|c|c|c|}
\hline \multirow[t]{2}{*}{ Time } & \multirow[t]{2}{*}{ ROI } & \multicolumn{3}{|c|}{ Overall effects } & \multicolumn{2}{|c|}{ Condition contrast $F(1,21)$} & \multicolumn{3}{|c|}{ Plac. - Alc. contrast $F(1,21)$} \\
\hline & & Cond. $\times$ Bev. $F(2,42)$ & Condition $F(2,42)$ & Beverage $F(1,21)$ & AN-SW & SW-PW & sw & AN & PW \\
\hline \multirow{6}{*}{$170-320 \mathrm{~ms}$} & L plPF & $3.9^{\dagger}$ & 1.7 & 3.7 & 0.1 & 3.1 & 3.2 & $5.7^{\dagger}$ & 1.4 \\
\hline & L LT & $8.0^{*}$ & 2.9 & 2.8 & 0.8 & $5.1^{\dagger}$ & $9.5^{*}$ & 2.4 & 0.4 \\
\hline & LACC & $6.5^{*}$ & 1.0 & $11.8^{*}$ & 0.3 & 0.6 & $17.6^{* *}$ & $5.6^{\dagger}$ & 0.1 \\
\hline & $\mathrm{R}$ plPF & 0.1 & 0.2 & 0.3 & 0.3 & 0.0 & 0.0 & 0.1 & 0.5 \\
\hline & R LT & 0.3 & 0.1 & $7.4^{+}$ & 0.0 & 0.1 & $7.2^{\dagger}$ & 2.6 & $4.8^{\dagger}$ \\
\hline & $\mathrm{R} A C C$ & 3.1 & 0.1 & 1.7 & 0.2 & 0.0 & 3.3 & 4.0 & 0.8 \\
\hline \multirow[t]{5}{*}{$370-520 \mathrm{~ms}$} & L alPF & 0.6 & $25.8 * * *$ & $9.8^{*}$ & $11.6^{*}$ & $30.4 * * *$ & $4.4^{\dagger}$ & $6.2^{\dagger}$ & 2.3 \\
\hline & L plPF & $5.8^{*}$ & $16.2^{* * *}$ & $6.8^{\dagger}$ & $4.7^{\dagger}$ & $19.3^{* *}$ & 3.3 & $12.7^{*}$ & 0.5 \\
\hline & L LT & $6.7^{*}$ & $10.1^{* *}$ & $8.3^{*}$ & 0.9 & $16.3^{* *}$ & $7.6^{\dagger}$ & $12.5^{*}$ & 1.0 \\
\hline & $\mathrm{R} L T$ & 0.2 & $3.4^{\dagger}$ & $9.0^{*}$ & $8.9 *$ & 0.0 & $4.8^{\dagger}$ & 3.9 & $5.4^{\dagger}$ \\
\hline & $\mathrm{R} A C C$ & 1.2 & $5.6^{*}$ & 1.1 & $5.4^{\dagger}$ & 0.3 & 0.5 & 2.0 & 0.0 \\
\hline \multirow[t]{2}{*}{$450-650 \mathrm{~ms}$} & $\mathrm{Cz}$ & $F(2,38)$ & $F(2,38)$ & $F(1,19)$ & \multicolumn{2}{|c|}{$F(1,19)$} & \multicolumn{3}{|c|}{$F(1,19)$} \\
\hline & & 2.3 & $26.0 * * *$ & $13.1^{*}$ & $16.7^{* *}$ & $15.2^{* *}$ & 3.6 & $7.0^{\dagger}$ & 1.5 \\
\hline
\end{tabular}

The associated $p$-values are marked as follows: ${ }^{\dagger} p<0.05,{ }^{*} p<0.01,{ }^{*} p<0.001,{ }^{* *} p<0.0001$.



FIGURE 5 | Group average total event-related power in theta frequency band recorded at $\mathrm{Cz}$ and expressed as relative change from the baseline. The timecourses for the three stimulus conditions are superimposed and shown for placebo and alcohol. The vertical shaded bars denote the 450-650 ms time window used in the statistical analysis.

Repeated measures ANOVA was carried out on theta power estimates averaged in the 450-650 ms latency window (Table 1). The strongest theta power was observed to the imperative AN words as compared to both SW and PW, $F(1,19)=29.2, p<0.0001$. Additionally, SW elicited stronger theta than PW, $F(1,19)=15.2$, $p<0.01$. While alcohol intoxication decreased theta power overall, $F(1,19)=13.1, p<0.001$, it did so especially for the AN condition, $F(1,19)=7.0, p<0.05$. Theta to SW was only marginally attenuated by intoxication, $F(1,19)=3.6, p<0.07$.

\section{DISCUSSION}

The unique application of the aMEG analysis in TF domain in the context of alcohol intoxication has revealed several findings pertaining to lexical-semantic processing. Event-related theta power estimated to the left-lateralized temporo-prefrontal cortex was sensitive to lexical-semantic retrieval during lexical decision task. Theta power estimated primarily to the lateral and medial prefrontal areas additionally reflected decision conflict on the imperative AN trials. Whereas alcohol reduced theta power overall across all processing stages, its effects were selective for the lexicalsemantic retrieval conditions as the theta to PW was not affected. This indicates that the synchronized activity in theta range underlies lexical-semantic retrieval in the left fronto-temporal areas which is vulnerable to alcohol intoxication. These effects are discussed seriatim in greater detail.

\section{LEXICAL-SEMANTIC RETRIEVAL}

Revealing the neurofunctional correlates of semantic processing has been the fundamental goal of neuroimaging of language function. Studies using the ERPs have explored extensively the effects of semantic, contextual, and lexical characteristics on the N400, a negative deflection peaking at $\sim 400 \mathrm{~ms}$ after the onset of a potentially meaningful stimulus (Kutas and Federmeier, 2000; Luck, 2005; Van Petten and Luka, 2006). One of the most commonly employed paradigms is a lexical decision task requiring participants to decide whether a presented letter string is a real, meaningful word or not. Pseudowords are often used as the control stimuli. A large number of ERP studies have reported that the N400 to pseudowords is larger than or equivalent to the N400 to real words (Bentin et al., 1985; Holcomb and Neville, 1990; Holcomb, 1993; Federmeier et al., 2000; Deacon et al., 2004; Laszlo and Federmeier, 2009; Vartiainen et al., 2011). While pseudowords resemble real words in that they obey the orthographic and phonotactic 
rules, they carry no meaning. Consequently, the N400 has been interpreted as an attempt to access and integrate a semantic representation into the current context (Halgren, 1990; Brown and Hagoort, 1993; Friederici, 1997; Kutas and Federmeier, 2000, 2011; Holcomb et al., 2002; Van Petten and Luka, 2006). In contrast to the time-domain studies, we have applied TF analysis which is sensitive to oscillatory dynamics. Our results clearly indicate that real words elicit stronger theta power than PW in the left temporoprefrontal areas associated with language processing. This finding is consistent with previous EEG evidence of theta sensitivity to the outcome of semantic retrieval (Bastiaansen and Hagoort, 2006). It has been shown that theta power is modulated by semantic incongruity within sentences (Hagoort et al., 2004; Hald et al., 2006) and word pairs that are thematically associated (Maguire et al., 2010). Theta also increases to nouns, verbs and adjectives (i.e., open class words) compared to semantically impoverished closed class words (e.g., prepositions; Bastiaansen et al., 2005). In a study manipulating visual vs. auditory semantic properties of the words embedded in a lexical decision task, Bastiaansen et al. (2008) observed that, unlike the N400, theta was uniquely sensitive to the modality-specific topography of the semantic representations. The specificity of theta oscillations to semantic retrieval is consistent with its increase during semantic priming (Salisbury and Taylor, 2012) and its engagement in memory functions, particularly during retrieval (Klimesch et al., 2001; Guderian and Duzel, 2005). Indeed, synchronous interactions between the hippocampus and the prefrontal cortex have been observed specifically in theta range, confirming the importance of theta in memory functions with intracranial EEG recordings in humans (Steinvorth et al., 2010) and animals (Jones and Wilson, 2005; Siapas et al., 2005; Sirota et al., 2008). Among other evidence, these observations provide the basis for the view that oscillatory changes across different frequency bands afford a way to study and conceptualize binding of large-scale distributed representations during cognition that may underlie conscious experience in general (Basar, 2006; Dehaene and Changeux, 2011; Siegel et al., 2012). The oscillatory nature of the EEG and MEG signals makes them suitable for studying neuronal activity that is not necessarily phase-locked with the stimulus since synchronous changes across local neuronal envelopes are reflected in the amplitude of the signal (Pfurtscheller and Lopes da Silva, 1999; Buszaki, 2006; Nunez and Srinivasan, 2006). Furthermore, transient phase coherence between distant brain areas is an indicator of functional interactions of distributed areas (Lachaux et al., 1999).

Our results show that real words (SW) are associated with greater event-related theta than pseudowords (PW) in the left temporo-prefrontal areas in contrast to previous time-domain MEG findings of larger or equal N400m to PW compared to SW (Wydell et al., 2003; Vartiainen et al., 2011). Similarly, a stronger activation of the left inferior prefrontal cortex has been observed to PW than to SW with BOLD-fMRI (Binder et al., 2003; Clark and Wagner, 2003; Burton et al., 2005). Some fMRI studies, however, show differential activity in the anterior vs. posterior inferior prefrontal cortex depending on the semantic and phonological task manipulations (Binder et al., 2003; Mechelli et al., 2005; Humphries et al., 2007). Taken together, these findings suggest that PW, which share the structural characteristics with SW, engage the semantic network during the search for semantic representations. Indeed, we acquire new words continually and many of the words that are currently contained in our vocabulary were initially perceived as PW. The words used in the present study had very low frequency $(4.3 \pm 2.4$ occurrences per million), which can explain the imperfect accuracy on SW $(90.9 \pm 7.2 \%)$. The low frequency of SW made the lexical decision task more difficult as some PW were categorized as real words (PW accuracy was $92.9 \pm 12.9 \%$ ). However, only the trials with correct responses were included in the aMEG analysis, assuring that erroneous processing did not confound the observed activity. Consequently, theta power to SW was associated with successful lexical-semantic access and retrieval. Even though both SW and PW are processed for orthographic and phonological dimensions, they differ in the actual access to semantic representations since only SW are associated with meaning. Therefore, significantly larger theta to SW than to PW uniquely demonstrates that theta is sensitive to semantic retrieval and may be used as an index of that process, further confirming the fundamental association between language and memory functions (Kutas and Federmeier, 2000; Hanslmayr et al., 2011). Future studies could explore the nature of PW processing and its similarity to SW processing further by manipulating the degree to which the PW are "wordlike" and to which they share their orthographic neighborhood with real words (Holcomb et al., 2002).

\section{SPATIO-TEMPORAL THETA ESTIMATES IN THE LEFT-LATERALIZED LANGUAGE NETWORK}

The extracranial EEG/MEG methods have to contend with the inherent uncertainty of the source estimation, their excellent temporal resolution notwithstanding (Cohen and Halgren, 2009). The estimation uncertainty results from a combination of influences including the signal propagation from the generator to the sensors, overlapping activity from different sources that is recorded by each sensor, and incomplete field sampling. Compared to EEG, MEG is little affected by the tissue interposed between the generators and sensors (Hämäläinen et al., 1993; Liu et al., 2002), and application of physiologically reasonable solution constraints permits disambiguation of the inverse problem in the context of multimodal integration (Dale and Sereno, 1993; Dale et al., 2000). The uncertainty is further influenced by the employed model which determines the permitted generator locations and the degree of their distribution, along with other parameters. The aMEG approach relies on the assumption that the synaptic currents giving rise to the summated MEG signal observed on the scalp are confined to the cortical ribbon (Dale et al., 2000). It applies a real head model obtained by reconstructing each person's cortical surface from high-resolution MRI to constrain a distributed minimum norm inverse solution (Dale and Sereno, 1993) and modeling studies indicate a reasonable localization accuracy given the applied assumptions (Liu et al., 2002). The TF analysis of the oscillatory signal developed in the context of the aMEG approach allowed us to obtain spatio-temporal estimates of the event-related theta changes associated with semantic retrieval and alcohol effects. In the present study, SW elicited stronger theta power compared to PW in the left LT and prefrontal cortices in the $\sim 370-520 \mathrm{~ms}$ time window. Both the temporal window and the spatial distribution of these effects correspond to the left-lateralized fronto-temporal 
network subserving the generation of the N400m analyzed in timedomain (Helenius et al., 1998; Dhond et al., 2001, 2005; Halgren et al., 2002; Marinkovic, 2004). These spatial estimates are also consistent with a large body of research based on the BOLD-fMRI method showing that the main foci of language-related activity are the left-lateralized temporal and prefrontal areas comparable to the ones observed in this study (for reviews see Fiez and Petersen, 1998; Badre and Wagner, 2002; Bookheimer, 2002; Binder et al., 2009; Liakakis et al., 2011).

Despite temporal smearing and the inferior resolution to that obtained with time-domain analysis, the wavelet-based estimates suggest that event-related theta power peaked in the LT cortex at $\sim 320 \mathrm{~ms}$ (Figure 2), preceding the activity in the PFC and consistent with our previous observations (Marinkovic et al., 2003). ROI analysis indicated that the SW elicited stronger theta than PW in the left LT at this latency. This difference was also observed in the left ACC under placebo and it continued during the subsequent time window, $\sim 370-520 \mathrm{~ms}$. Importance of the left temporal lobe in semantic functions has been confirmed in numerous studies. ERPs recorded intracranially from epilepsy patients offer a unique opportunity to examine the generators of the ERPs recorded on the scalp. Such studies confirm that the anteroventral temporal cortices are the main generators of the N400 (Halgren et al., 1994; Nobre et al., 1994), with word-specific potentials recorded in the LT areas as well (Halgren et al., 1994). Lesions of the left temporal lobe result in impaired semantic comprehension at the single-word level (Hart and Gordon, 1990; Dronkers et al., 2004). Furthermore, the gradient of atrophy in the temporal cortex is specifically related to deficits in semantic memory in patients suffering from semantic dementia (Mummery et al., 2000; Rogers et al., 2006). Neuroimaging studies confirm that the LT cortex is involved specifically during semantic retrieval (Gold and Buckner, 2002; Noppeney et al., 2004; Ruff et al., 2008).

In the present study, the peak of theta power was estimated to the anterior (aIPF) and posterior (pIPF) inferior prefrontal cortices at $\sim 450 \mathrm{~ms}$ (Figure 3 ). Theta power was significantly greater to SW than to PW. Both of these areas have been implicated in lexical decision tasks. Numerous BOLD-fMRI studies have observed activity in the aIPF during semantic processing (Bookheimer, 2002; Binder et al., 2009), although the exact nature and the semantic specificity of its contribution has been debated (Thompson-Schill et al., 1997; Wagner et al., 2001). Evidence suggests that the pIPF is particularly activated by tasks relying on phonological processing (Poldrack et al., 1999; Binder et al., 2009). This area is commonly more activated by PW than real words during lexical decision making (Clark and Wagner, 2003; Burton et al., 2005), in agreement with its proposed role in phonological processing (Hickok and Poeppel, 2007; Burton, 2009). Furthermore, it is activated across both visual and auditory modalities, suggesting a supramodal role in lexical access (Heim et al., 2007). During a lexical decision task each new stimulus has to be evaluated for its phonological and semantic "verity." The parallel engagement of the anterior and posterior prefrontal cortices observed in the present study is consistent with BOLD-fMRI studies. Nonetheless, our results indicate that in all lateral temporo-prefrontal areas, greater event-related theta is associated with real words and successful semantic retrieval, reinforcing the idea that theta power may reflect the binding of distributed representations (Siegel et al., 2012). EEG theta power estimates (Figure 5) lack the spatial dimension provided by aMEG, but they correspond with the main findings inasmuch as the AN elicited the strongest theta power, followed by SW. In contrast, very little EEG theta was elicited by $\mathrm{PW}$, consistent with the idea that theta is primarily sensitive to the outcome of semantic retrieval (Bastiaansen and Hagoort, 2006).

In addition to the lateral temporo-prefrontal areas, theta estimated to the ACC was greater to SW than to PW under placebo. As discussed in greater detail below, the ACC contributes to a variety of tasks that require monitoring of potential conflict. The present results along with other evidence, suggest that it is also involved in semantic processing across sensory modalities (Marinkovic et al., 2003). A functional connectivity study (Stamatakis et al., 2005) showed that the ACC modulated the interactions between the left IPF and middle temporal gyrus during processing of words that differed in the inflection regularity. Concurrent engagement of the temporo-fronto-cingulate network seems to indicate that the semantic retrieval in the context of an executive task is subserved by a distributed system (Gold and Buckner, 2002; Noppeney et al., 2004; Binder et al., 2009). Relative contributions of these areas depend on task parameters such as difficulty, depth of semantic processing, and semantic retrieval relies upon memory search, selection, response selection, and execution.

In the present study, moderate alcohol intoxication reduced event-related theta overall, starting with the visual sensory processing estimated to the occipital cortex. However, it is particularly deleterious to semantic processing, given that theta power was reduced to SW while the theta elicited by PW was unchanged. Therefore, it appears that alcohol impairs matching of semantic representations with word stimuli, but not the orthographic, phonological, phonotactic, or other aspects of evaluation that are involved in PW processing. This finding is broadly consistent with behavioral studies reporting alcohol-induced impairments of semantic memory (Maylor et al., 1990; Acheson et al., 1998). It holds promise for using lexical decision task to investigate semantic retrieval in patient populations or under other pharmacological manipulations.

\section{EFFECTS OF DECISION CONFLICT AND ALCOHOL}

Greater theta power to SW as compared to PW suggests its selective sensitivity to semantic retrieval since only the SW were associated with semantic representations. Our task comprised another level of response contingency, allowing us to further contrast the event-related theta power to SW and to imperative words in the context of a double-duty paradigm. In addition to detecting real words, the participants were asked to respond if a real word also denoted an animal. Both SW and AN conditions were associated with semantic representations and in both cases they required an active response. This contingency insured that both SW and AN words were evaluated on the semantic dimension since subjects had to retrieve the actual meaning of each word and compare it to the "animal lexicon." Conversely, it is possible that they adopted a strategy of searching for members of the "animal category" before deciding whether a word is real or not. The overall RTs to SW and AN did not differ, but alcohol intoxication significantly increased response times, consistent with its effects on semantic retrieval. 
The AN accuracy was lower than in SW and PW conditions, indicating increased difficulty on these imperative trial, which is due in part to a lower familiarity with some of the less common animal species. In addition, AN trials demanded increased cognitive control since fewer AN than SW trials were presented in the context of the task. However, the aMEG analysis comprised only those trials on which correct responses were given. Furthermore, task and beverage conditions were equated for the number of included trials in an effort to remove any potential bias.

A direct comparison of theta estimates to $\mathrm{AN}$ and $\mathrm{SW}$ is shown in Figure 4. Theta power did not differ between the AN and SW conditions in LT area, since they both relied on lexical-semantic access subserved by the temporal cortex (Halgren et al., 1994; Dronkers et al., 2004; Ruff et al., 2008). However, the AN condition elicited stronger theta power than SW in both anterior and posterior inferoprefrontal regions (Table 1). This finding indicates that the inferior prefrontal cortex is sensitive to task difficulty since detecting "animals" as a special semantic category imposed demands on the controlled access to the semantic domain that exceeded mere access to the lexical form. This interpretation is consistent with similar findings in BOLD-fMRI studies showing that task difficulty results in increased activity in inferior prefrontal cortex (Gold and Buckner, 2002; Binder et al., 2009). In addition, the ACC also showed greater theta power to AN than SW. Greater engagement of the ACC during a semantically more demanding task as compared to the lexical decision was similarly reported by Ruff et al. (2008). Indeed, extensive evidence points to the ACC as a central node in a frontal cortical network subserving controlled processing (Paus, 2001; Ridderinkhof et al., 2004; Botvinick, 2007; Carter and Van Veen, 2007; Posner et al., 2007). Widespread anatomical connections of the ACC with lateral frontal areas, limbic structures, the motor cortex, and other levels of the neuraxis make the ACC suitable for its multifaceted role in monitoring for conflict and regulating actions (Devinsky et al., 1995; Barbas, 2000; Bush et al., 2000). Our previous studies confirm the ACC's sensitivity to task conflict and difficulty as reflected in event-related theta power (Kovacevic et al., submitted) and confirmed with BOLD-fMRI (Marinkovic et al., 2012). Furthermore, in those studies alcohol intoxication especially attenuated the ACC activity, suggesting that the top-down regulatory functions are most vulnerable to moderate intoxication. In the present study, the effects of alcohol were specific to the event-related theta associated with semantic retrieval and the executive dimension. These two functions appear to be supported by highly overlapping neurofunctional systems that were engaged by the double-duty

\section{REFERENCES}

Acheson, S. K., Stein, R. M., and Swartzwelder, H. S. (1998). Impairment of semantic and figural memory by acute ethanol: age-dependent effects. Alcohol. Clin. Exp. Res. 22, 1437-1442.

Andrew, C., and Fein, G. (2010). Eventrelated oscillations versus eventrelated potentials in a P300 task as biomarkers for alcoholism. Alcohol. Clin. Exp. Res. 34, 669-680.
Badre, D., and Wagner, A. D. (2002). Semantic retrieval, mnemonic control, and prefrontal cortex. Behav. Cogn. Neurosci. Rev. 1, 206-218.

Barbas, H. (2000). Connections underlying the synthesis of cognition, memory, and emotion in primate prefrontal cortices. Brain Res. Bull. 52, 319-330.

Basar, E. (2006). The theory of the whole-brain-work. Int. J. Psychophysiol. 60, 133-138. task. The left-lateralized fronto-temporal cortex subserves lexicalsemantic retrieval, as indicated by the sensitivity of theta power to real words, but not pseudowords. Additionally, a somewhat bilateral fronto-cingulate network was additionally activated by increased task demands during AN, consistent with right temporoprefrontal contributions during attention-demanding processing oddball patterns (Halgren et al., 2011). An indirect confirmation of the spatial estimates obtained in the current study and their relative sensitivity to both semantic retrieval and difficulty is provided by a BOLD-fMRI study carried out by Sabsevitz et al. (2005). They manipulated the difficulty of a semantic judgment task and found that abstract nouns activated left temporal and inferior frontal cortex. This strongly converges with our observation that theta power was elicited by real words in the left-lateralized language system. In contrast, the activity in a more bilateral lateral prefrontal and medial ACC network was modulated by increased difficulty demands in both our study, and the Sabsevitz et al. study. These convergent findings suggest that different neurofunctional networks contribute to successful performance in an interactive and flexible manner, as they are sensitive to the semantic dimension, but also rely on more general functions such as attention, working memory, response monitoring, and optimization, etc. (Noppeney et al., 2004; Binder et al., 2009). Consequently, moderate alcohol intoxication impairs semantic retrieval and decreases the efficiency of controlled processing. It also affects response preparation and execution, as reflected in weaker theta power in hand-centered motor areas under intoxication.

In sum, the magnitude of event-related theta power was sensitive to the two functions manipulated by the double-duty lexical decision task. First, theta estimated to the left-lateralized fronto-temporal areas reflected lexical-semantic retrieval which was selectively attenuated by alcohol intoxication. Second, a highly overlapping prefrontal network comprising lateral prefrontal and ACC was sensitive to decision making and was also affected by intoxication, in agreement with previous studies indicating that alcohol's effects are deleterious to executive functions.

\section{ACKNOWLEDGMENTS}

This work was supported by funds from the National Institutes of Health (K01-AA13402, R01-AA016624, and RR031599), and Medical Investigation of Neurodevelopmental Disorders (MIND) Institute. The data were collected at Martinos Center for Biomedical Imaging, Massachusetts General Hospital, Charlestown, MA, USA. We thank Ryan O'Hara, Jason Sherfey, Donald Hagler, Andrew Schulman, and Jonathan Dan for assistance.
Bastiaansen, M., and Hagoort, P. (2006). Oscillatory neuronal dynamics during language comprehension. Prog. Brain Res. 159, 179-196.

Bastiaansen, M. C., Oostenveld, R. Jensen, O., and Hagoort, P. (2008). I see what you mean: theta power increases are involved in the retrieval of lexical semantic information. Brain Lang. 106, 15-28.

Bastiaansen, M. C., Van Der Linden, M., Ter Keurs, M., Dijkstra,
T., and Hagoort, P. (2005). Theta responses are involved in lexicalsemantic retrieval during language processing. J. Cogn. Neurosci. 17, 530-541.

Begleiter, H., and Porjesz, B. (2006). Genetics of human brain oscillations. Int. J. Psychophysiol. 60, 162-171.

Bentin, S., Mccarthy, G., and Wood, C. C. (1985). Event-related potentials, lexical decision and 
semantic priming. Electroencephalogr. Clin. Neurophysiol. 60, 343-355.

Binder, J. R., Desai, R. H., Graves, W. W., and Conant, L. L. (2009). Where is the semantic system? A critical review and meta-analysis of 120 functional neuroimaging studies. Cereb. Cortex 19, 2767-2796.

Binder, J. R., Mckiernan, K. A., Parsons, M. E., Westbury, C. F., Possing, E. T., Kaufman, J. N., and Buchanan, L. (2003). Neural correlates of lexical access during visual word recognition. J. Cogn. Neurosci. 15, 372-393.

Bookheimer, S. (2002). Functional MRI of language: new approaches to understanding the cortical organization of semantic processing. Annu. Rev. Neurosci. 25, 151-188.

Botvinick, M. M. (2007). Conflict monitoring and decision making: reconciling two perspectives on anterior cingulate function. Cogn. Affect. Behav. Neurosci. 7, 356-366.

Brier, M. R., Ferree, T. C., Maguire, M. J., Moore, P., Spence, J., Tillman, G. D., Hart, J. Jr., and Kraut, M. A. (2010). Frontal theta and alpha power and coherence changes are modulated by semantic complexity in Go/NoGo tasks. Int. J. Psychophysiol. 78, 215-224.

Brown, C., and Hagoort, P. (1993). The processing nature of the N400: evidence from masked priming. J. Cogn. Neurosci. 5, 34-44.

Burton, M. W. (2009). Understanding the role of the prefrontal cortex in phonological processing. Clin. Linguist. Phon. 23, 180-195.

Burton, M. W., Locasto, P. C., KrebsNoble, D., and Gullapalli, R. P. (2005). A systematic investigation of the functional neuroanatomy of auditory and visual phonological processing. Neuroimage 26, 647-661.

Bush, G., Luu, P., and Posner, M. I. (2000). Cognitive and emotional influences in anterior cingulate cortex. Trends Cogn. Sci. (Regul. Ed.) 4, 215-222.

Buszaki, G. (2006). Rhythms of the Brain. New York: Oxford University Press.

Cahalan, D., Cisin, I. H., and Crossley, H. M. (1969). American Drinking Practices: A National Study of Drinking Behavior and Attitudes. Monograph \#6. New Brunswick, NJ: Rutgers Center of Alcohol Studies.

Carter, C. S., and Van Veen, V. (2007). Anterior cingulate cortex and conflict detection: an update of theory and data. Cogn. Affect. Behav. Neurosci. 7, 367-379.

Clark, D., and Wagner, A. D. (2003). Assembling and encoding word representations: fMRI subsequent memory effects implicate a role for phonological control. Neuropsychologia 41, 304-317.

Cohen, D., and Halgren, E. (2009). "Magnetoencephalography," in Encyclopedia of Neuroscience, ed. L. R. Squire (Oxford: Academic Press), 615-622.

Dale, A. M., Fischl, B., and Sereno, M. I. (1999). Cortical surface-based analysis. I. Segmentation and surface reconstruction. Neuroimage 9, 179-194.

Dale, A. M., Liu, A. K., Fischl, B. R., Buckner, R. L., Belliveau, J. W., Lewine, J. D., and Halgren, E. (2000). Dynamic statistical parametric mapping: combining fMRI and MEG for high-resolution imaging of cortical activity. Neuron 26, 55-67.

Dale, A. M., and Sereno, M. I. (1993). Improved localization of cortical activity by combining EEG and MEG with MRI cortical surface reconstruction: a linear approach. J. Cogn. Neurosci. 5, 162-176.

Deacon, D., Dynowska, A., Ritter, W., and Grose-Fifer, J. (2004). Repetition and semantic priming of nonwords: implications for theories of N400 and word recognition. Psychophysiology 41, 60-74.

Dehaene, S., and Changeux, J. P. (2011). Experimental and theoretical approaches to conscious processing. Neuron 70, 200-227.

Delorme, A., and Makeig, S. (2004). EEGLAB: an open source toolbox for analysis of single-trial EEG dynamics. J. Neurosci. Methods 134, 9-21.

Devinsky, O., Morrell, M. J., and Vogt, B. A. (1995). Contributions of anterior cingulate cortex to behaviour. Brain 118(Pt 1), 279-306.

Dhond, R. P., Buckner, R. L., Dale, A. M., Marinkovic, K., and Halgren, E. (2001). Sequence of brain activity underlying word-stem completion. J. Neurosci. 21, 3564-3571.

Dhond, R. P., Witzel, T., Dale, A. M., and Halgren, E. (2005). Spatiotemporal brain maps of delayed word repetition and recognition. Neuroimage 28, 293-304.

Dhond, R. P., Witzel, T., Dale, A. M., and Halgren, E. (2007). Spatiotemporal cortical dynamics underlying abstract and concrete word reading. Hum. Brain Mapp. 28, 355-362.

Dronkers, N. F., Wilkins, D. P., Van Valin, R. D. Jr., Redfern, B. B., and Jaeger, J. J. (2004). Lesion analysis of the brain areas involved in language comprehension. Cognition 92, 145-177.

Eysenck, H. J., and Eysenck, S. B. G. (1975). Manual of the Eysenck
Personality Questionnaire. London: Hodder \& Staughton.

Federmeier, K. D., Segal, J. B., Lombrozo, T., and Kutas, M. (2000). Brain responses to nouns, verbs and class-ambiguous words in context. Brain 123(Pt 12), 2552-2566.

Fiez, J. A., and Petersen, S. E. (1998). Neuroimaging studies of word reading. Proc. Natl. Acad. Sci. U.S.A. 95, 914-921.

Fischl, B., Sereno, M. I., and Dale, A. M. (1999a). Cortical surface-based analysis. II: inflation, flattening, and a surface-based coordinate system. Neuroimage 9, 195-207.

Fischl, B., Sereno, M. I., Tootell, R. B., and Dale, A. M. (1999b). High-resolution intersubject averaging and a coordinate system for the cortical surface. Hum. Brain Mapp. 8, 272-284.

Francis, W. N., and Kucera, H. (1982). Frequency analysis of English usage: Lexicon and grammar. Boston: Houghton Mifflin.

Friederici, A. D. (1997). Neurophysiological aspects of language processing. Clin. Neurosci. 4, 64-72.

Garfinkel, S. N., Dienes, Z., and Duka, T. (2006). The effect of alcohol and repetition at encoding on implicit and explicit false memories. Psychopharmacology (Berl.) 188 , 498-508.

Gold, B. T., and Buckner, R. L. (2002). Common prefrontal regions coactivate with dissociable posterior regions during controlled semantic and phonological tasks. Neuron 35 , 803-812.

Gough, H. G. (1994). Theory, development, and interpretation of the CPI socialization scale. Psychol. Rep. 75, 651-700.

Guderian, S., and Duzel, E. (2005). Induced theta oscillations mediate large-scale synchrony with mediotemporal areas during recollection in humans. Hippocampus $15,901-912$.

Hagoort, P., Hald, L., Bastiaansen, M., and Petersson, K. M. (2004). Integration of word meaning and world knowledge in language comprehension. Science 304, 438-441.

Hald, L. A., Bastiaansen, M. C., and Hagoort, P. (2006). EEG theta and gamma responses to semantic violations in online sentence processing. Brain Lang. 96, 90-105.

Halgren, E. (1990). "Insights from evoked potentials into the neuropsychological mechanisms of reading," in Neurobiology of Higher Cognitive Function, eds A. B. Scheibel and A. F. Wechsler (New York: Guilford), 103-150.
Halgren, E., Baudena, P., Heit, G., Clarke, J. M., and Marinkovic, K. (1994). Spatio-temporal stages in face and word processing. I. Depthrecorded potentials in the human occipital, temporal and parietal lobes [corrected] [published erratum appears in J. Physiol. Paris 1994;88(2):following 151]. J. Physiol. Paris $88,1-50$.

Halgren, E., Dhond, R. P., Christensen, N., Van Petten, C., Marinkovic, K., Lewine, J. D., and Dale, A. M. (2002). N400-like magnetoencephalography responses modulated by semantic context, word frequency, and lexical class in sentences. Neuroimage 17, 1101-1116.

Halgren, E., Sherfey, J., Irimia, A., Dale, A. M., and Marinkovic, K. (2011). Sequential temporo-frontotemporal activation during monitoring of the auditory environment for temporal patterns. Hum. Brain Mapp. 32, 1260-1276.

Hämäläinen, M., Hari, R., Ilmoniemi, R. J., Knuutila, J., and Lounasmaa, O. V. (1993). Magnetoencephalography - theory, instrumentation, and applications to noninvasive studies of the working human brain. Rev. Mod. Phys. 65, 413-497.

Hanslmayr, S., Volberg, G., Wimber M., Raabe, M., Greenlee, M. W., and Bauml, K. H. (2011). The relationship between brain oscillations and BOLD signal during memory formation: a combined EEG-fMRI study. J. Neurosci. 31, 15674-15680.

Hart, J. Jr., and Gordon, B. (1990). Delineation of single-word semantic comprehension deficits in aphasia, with anatomical correlation. Ann. Neurol. 27, 226-231.

Heim, S., Eickhoff, S. B., Ischebeck, A. K., Supp, G., and Amunts, K. (2007). Modality-independent involvement of the left BA 44 during lexical decision making. Brain Struct. Funct. 212, 95-106.

Helenius, P., Salmelin, R., Service, E., and Connolly, J. F. (1998). Distinct time courses of word and context comprehension in the left temporal cortex. Brain 121, 1133-1142.

Hickok, G., and Poeppel, D. (2007). The cortical organization of speech processing. Nat. Rev. Neurosci. 8, 393-402.

Holcomb, P. J. (1993). Semantic priming and stimulus degradation: implications for the role of the N400 in language processing. Psychophysiology 30, 47-61.

Holcomb, P. J., Grainger, J., and O'rourke, T. (2002). An electrophysiological study of the effects of orthographic neighborhood size on 
printed word perception. J. Cogn. Neurosci. 14, 938-950.

Holcomb, P. J., and Neville, H. (1990). Semantic priming in visual and auditory lexical decision: a between modality comparison. Lang. Cogn. Process. 5, 281-312.

Humphries, C., Binder, J. R., Medler, D. A., and Liebenthal, E. (2007). Time course of semantic processes during sentence comprehension: an fMRI study. Neuroimage 36, 924-932.

Jensen, O., and Tesche, C. D. (2002). Frontal theta activity in humans increases with memory load in a working memory task. Eur. J. Neurosci. 15, 1395-1399.

Johnson-Greene, D., Adams, K. M., Gilman, S., Koeppe, R. A., Junck, L., Kluin, K. J., Martorello, S., and Heumann, M. (1997). Effects of abstinence and relapse upon neuropsychological function and cerebral glucose metabolism in severe chronic alcoholism. J. Clin. Exp. Neuropsychol. 19, 378-385.

Jones, M. W., and Wilson, M. A. (2005). Theta rhythms coordinate hippocampal-prefrontal interactions in a spatial memory task. PLoS Biol. 3, e402. doi:10.1371/journal.pbio.0030402

Kamarajan, C., Porjesz, B., Jones, K., Chorlian, D., Padmanabhapillai, A., Rangaswamy, M., Stimus, A., and Begleiter, H. (2006). Event-related oscillations in offspring of alcoholics: neurocognitive disinhibition as a risk for alcoholism. Biol. Psychiatry 59, 625-634.

Kamarajan, C., Porjesz, B., Jones, K. A., Choi, K., Chorlian, D. B., Padmanabhapillai, A., Rangaswamy, M., Stimus, A. T., and Begleiter, $\mathrm{H}$. (2004). The role of brain oscillations as functional correlates of $\operatorname{cog}$ nitive systems: a study of frontal inhibitory control in alcoholism. Int. J. Psychophysiol. 51, 155-180.

Klimesch, W. (1999). EEG alpha and theta oscillations reflect cognitive and memory performance: a review and analysis. Brain Res. Brain Res. Rev. 29, 169-195.

Klimesch, W., Doppelmayr, M., Stadler, W., Pollhuber, D., Sauseng, P., and Rohm, D. (2001). Episodic retrieval is reflected by a process specific increase in human electroencephalographic theta activity. Neurosci. Lett. 302, 49-52.

Koelega, H. S. (1995). Alcohol and vigilance performance: a review. Psychopharmacology (Berl.) 118, 233-249.

Krause, C. M., Aromaki, A., Sillanmaki, L., Astrom, T., Alanko, K., Salonen,
E., and Peltola, O. (2002). Alcoholinduced alterations in ERD/ERS during an auditory memory task. Alcohol 26, 145-153.

Kutas, M., and Federmeier, K. D. (2000). Electrophysiology reveals semantic memory use in language comprehension. Trends Cogn. Sci. (Regul. Ed.) 4, 463-470.

Kutas, M., and Federmeier, K. D. (2011). Thirty years and counting: finding meaning in the N400 component of the event-related brain potential (ERP). Annu. Rev. Psychol. 62, 621-647.

Lachaux, J. P., Rodriguez, E., Martinerie, J., and Varela, F. J. (1999). Measuring phase synchrony in brain signals. Hum. Brain Mapp. 8, 194-208.

Laszlo, S., and Federmeier, K. D. (2009). A beautiful day in the neighborhood: an event-related potential study of lexical relationships and prediction in context. J. Mem. Lang. 61, 326-338.

Liakakis, G., Nickel, J., and Seitz, R. J. (2011). Diversity of the inferior frontal gyrus-a meta-analysis of neuroimaging studies. Behav. Brain Res. 225, 341-347.

Lin, F. H., Witzel, T., Hamalainen, M. S., Dale, A. M., Belliveau, J. W., and Stufflebeam, S. M. (2004). Spectral spatiotemporal imaging of cortical oscillations and interactions in the human brain. Neuroimage 23, 582-595.

Lister, R. G., Gorenstein, C., FisherFlowers, D., Weingartner, H. J., and Eckardt, M. J. (1991). Dissociation of the acute effects of alcohol on implicit and explicit memory processes. Neuropsychologia 29, 1205-1212.

Liu, A. K., Dale, A. M., and Belliveau, J. W. (2002). Monte Carlo simulation studies of EEG and MEG localization accuracy. Hum. Brain Mapp. 16, $47-62$.

Luck, S. J. (2005). An introduction to the event-related potential technique. Cambridge, MA: MIT Press.

Lyvers, M. (2000). "Loss of control" in alcoholism and drug addiction: a neuroscientific interpretation. Exp. Clin. Psychopharmacol. 8, 225-249.

Maguire, M. J., Brier, M. R., and Ferree, T. C. (2010). EEG theta and alpha responses reveal qualitative differences in processing taxonomic versus thematic semantic relationships. Brain Lang. 114, 16-25.

Maltzman, I., and Marinkovic, K. (1996). "Alcohol, alcoholism, and the autonomic nervous system: a critical account," in The Pharmacology of Alcohol and Alcohol Dependence, eds
H. Begleiter and B. Kissin (New York: Oxford University Press), 248-306.

Marinkovic, K. (2004). Spatiotemporal dynamics of word processing in the human cortex. Neuroscientist 10 , 142-152.

Marinkovic, K., and Azma, S. (2010). Neural dynamics of alcohol effects on cognitive control: Eriksen flanker task. IFMBE Proc. 28, 374-377.

Marinkovic, K., Cox, B., Reid, K., and Halgren, E. (2004a). Head position in the MEG helmet affects the sensitivity to anterior sources. Neurol. Clin. Neurophysiol. 2004, 30.

Marinkovic, K., Halgren, E., and Maltzman, I. (2004b). Effects of alcohol on verbal processing: an ERP study. Alcohol. Clin. Exp. Res. 28, 415-423.

Marinkovic, K., Dhond, R. P., Dale, A. M., Glessner, M., Carr, V., and Halgren, E. (2003). Spatiotemporal dynamics of modality-specific and supramodal word processing. $\mathrm{Neu}$ ron 38, 487-497.

Marinkovic, K., Halgren, E., Klopp, J., and Maltzman, I. (2000). Alcohol effects on movement-related potentials: a measure of impulsivity? $J$. Stud. Alcohol 61, 24-31.

Marinkovic, K., Halgren, E., and Maltzman, I. (2001). Arousal-related P3a to novel auditory stimuli is abolished by moderately low alcohol dose. Alcohol Alcohol. 36, 529-539.

Marinkovic, K., Rickenbacher, E., Azma, S., and Artsy, E. (2012). Acute alcohol intoxication impairs top-down regulation of Stroop incongruity as revealed by blood oxygen leveldependent functional magnetic resonance imaging. Hum. Brain Mapp. 33, 319-333.

Martin, C. S., Earleywine, M., Musty, R. E., Perrine, M. W., and Swift, R. M. (1993). Development and validation of the Biphasic Alcohol Effects Scale. Alcohol. Clin. Exp. Res. 17, 140-146.

Maylor, E. A., Rabbitt, P. M., James, G. H., and Kerr, S. A. (1990). Comparing the effects of alcohol and intelligence on text recall and recognition. Br. J. Psychol. 81, 299-313.

McEvoy, L. K., Pellouchoud, E., Smith, M. E., and Gevins, A. (2001). Neurophysiological signals of working memory in normal aging. Brain Res. Cogn. Brain Res. 11, 363-376.

Mechelli, A., Crinion, J. T., Long, S., Friston, K. J., Lambon Ralph, M. A., Patterson, K., Mcclelland, J. L., and Price, C. J. (2005). Dissociating reading processes on the basis of neuronal interactions. J. Cogn. Neurosci. 17, 1753-1765.

Moselhy, H. F., Georgiou, G., and Kahn, A. (2001). Frontal lobe changes in alcoholism: a review of the literature. Alcohol Alcohol. 36, 357-368.

Mummery, C. J., Patterson, K., Price, C. J., Ashburner, J., Frackowiak, R. S., and Hodges, J. R. (2000). A voxel-based morphometry study of semantic dementia: relationship between temporal lobe atrophy and semantic memory. Ann. Neurol. 47, 36-45.

Mungas, D., Ehlers, C. L., and Wall, T. L. (1994). Effects of acute alcohol administration on verbal and spatial learning. Alcohol Alcohol. 29, 163-169.

Nixon, S. J., Tivis, R., Ceballos, N., Varner, J. L., and Rohrbaugh, J. (2002). Neurophysiological efficiency in male and female alcoholics. Prog. Neuropsychopharmacol. Biol. Psychiatry 26, 919-927.

Nixon, S. J., Tivis, R., and Parsons, O. A. (1995). Behavioral dysfunction and cognitive efficiency in male and female alcoholics. Alcohol. Clin. Exp. Res. 19, 577-581.

Nobre, A. C., Allison, T., and Mccarthy, G. (1994). Word recognition in the human inferior temporal lobe. Nature 372, 260-263.

Noppeney, U., Phillips, J., and Price, C. (2004). The neural areas that control the retrieval and selection of semantics. Neuropsychologia 42, 1269-1280.

Nunez, P. L., and Srinivasan, R. (2006). Electric Fields of the Brain: The Neurophysics of EEG. New York: Oxford University Press.

Oldfield, R. C. (1971). The assessment and analysis of handedness: the Edinburgh inventory. Neuropsychologia 9, 97-113.

Oostenveld, R., Fries, P., Maris, E., and Schoffelen, J. M. (2011). FieldTrip: open source software for advanced analysis of MEG, EEG, and invasive electrophysiological data. Comput. Intell Neurosci. 2011, 156869.

Oscar-Berman, M. (2000). "Neuropsychological vulnerabilities in chronic alcoholism," in Review of NIAAA's Neuroscience and Behavioral Research Portfolio, eds A. Noronha, M. Eckardt, and K. Warren (Bethesda, MD: National Institute on Alcohol Abuse and Alcoholism), 149-158.

Oscar-Berman, M., and Hutner, N. (1993). "Frontal lobe changes after chronic alcohol ingestion," in Alcohol-Induced Brain Damage, eds W. A. Hunt and S. J. Nixon (Rockville, MD: Department of Health and Human Services), 121-156.

Oscar-Berman, M., and Marinkovic, K. (2007). Alcohol: effects on 
neurobehavioral functions and the brain. Neuropsychol. Rev. 17, 239-257.

Oscar-Berman, M., and Schendan, $\mathrm{H}$. E. (2000). "Asymmetries of brain function in alcoholism: relationship to aging," in Neurobehavior of Language and Cognition: Studies of Normal Aging and Brain Damage, eds L. Obler and L. T. Connor (New York: Kluwer Academic Publishers).

Parsons, O. A. (1987). Intellectual impairment in alcoholics: persistent issues. Acta Med. Scand. Suppl. 717, 33-46.

Paulus, M. P., Tapert, S. F., Pulido, C., and Schuckit, M. A. (2006). Alcohol attenuates load-related activation during a working memory task: relation to level of response to alcohol. Alcohol. Clin. Exp. Res. 30, 1363-1371.

Paus, T. (2001). Primate anterior cingulate cortex: where motor control, drive and cognition interface. Nat. Rev. Neurosci. 2, 417-424.

Pfurtscheller, G., and Lopes da Silva, F. H. (1999). Event-related EEG/MEG synchronization and desynchronization: basic principles. Clin. Neurophysiol. 110, 1842-1857.

Poldrack, R. A., Wagner, A. D., Prull, M. W., Desmond, J. E., Glover, G. H., and Gabrieli, J. D. (1999). Functional specialization for semantic and phonological processing in the left inferior prefrontal cortex. Neuroimage $10,15-35$.

Porjesz, B., Rangaswamy, M., Kamarajan, C., Jones, K. A., Padmanabhapillai, A., and Begleiter, H. (2005). The utility of neurophysiological markers in the study of alcoholism. Clin. Neurophysiol. 116, 993-1018.

Posner, M. I., Rothbart, M. K., Sheese, B. E., and Tang, Y. (2007). The anterior cingulate gyrus and the mechanism of self-regulation. Cogn. Affect. Behav. Neurosci. 7, 391-395.

Rangaswamy, M., Jones, K. A., Porjesz, B., Chorlian, D. B., Padmanabhapillai, A., Kamarajan, C., Kuperman, S., Rohrbaugh, J., O'connor, S. J., Bauer, L. O., Schuckit, M. A., and Begleiter, H. (2007). Delta and theta oscillations as risk markers in adolescent offspring of alcoholics. Int. J. Psychophysiol. 63, 3-15.

Ray, S., Bates, M. E., and Ely, B. M. (2004). Alcohol's dissociation of implicit and explicit memory processes: implications of a parallel distributed processing model of semantic priming. Exp. Clin. Psychopharmacol. 12, 118-125.

Ridderinkhof, K. R., Van Den Wildenberg, W. P., Segalowitz, S. J., and Carter, C. S. (2004). Neurocognitive mechanisms of cognitive control: the role of prefrontal cortex in action selection, response inhibition, performance monitoring, and reward-based learning. Brain Cogn. 56, 129-140.

Rogers, T. T., Hocking, J., Noppeney, U., Mechelli, A., Gorno-Tempini, M. L., Patterson, K., and Price, C. J. (2006). Anterior temporal cortex and semantic memory: reconciling findings from neuropsychology and functional imaging. Cogn. Affect. Behav. Neurosci. 6, 201-213.

Roopesh, B. N., Rangaswamy, M., Kamarajan, C., Chorlian, D. B., Pandey, A. K., and Porjesz, B. (2010). Reduced resource optimization in male alcoholics: N400 in a lexical decision paradigm. Alcohol. Clin. Exp. Res. 34, 1905-1914.

Roopesh, B. N., Rangaswamy, M., Kamarajan, C., Chorlian, D. B., Stimus, A., Bauer, L. O., Rohrbaugh, J., O'connor, S. J., Kuperman, S., Schuckit, M., and Porjesz, B. (2009). Priming deficiency in male subjects at risk for alcoholism: the N4 during a lexical decision task. Alcohol. Clin. Exp. Res. 33, 2027-2036.

Ruff, I., Blumstein, S. E., Myers, E. B., and Hutchison, E. (2008). Recruitment of anterior and posterior structures in lexical-semantic processing: an fMRI study comparing implicit and explicit tasks. Brain Lang. 105, 41-49.

Sabsevitz, D. S., Medler, D. A., Seidenberg, M., and Binder, J. R. (2005). Modulation of the semantic system by word imageability. Neuroimage 27, 188-200.

Salisbury, D. F., and Taylor, G. (2012). Semantic priming increases left hemisphere theta power and intertrial phase synchrony. Psychophysiology 49, 305-311.

Selzer, M. L. (1971). The Michigan alcoholism screening test: the quest for a new diagnostic instrument. Am. J. Psychiatry 127, 1653-1658.
Selzer, M. L., Vinokur, A., and Van Rooijen, L. (1975). A self-administered Short Michigan Alcoholism Screening Test (SMAST). J. Stud. Alcohol 36, 117-126.

Siapas, A. G., Lubenov, E. V., and Wilson, M. A. (2005). Prefrontal phase locking to hippocampal theta oscillations. Neuron 46, 141-151.

Siegel, M., Donner, T. H., and Engel, A. K. (2012). Spectral fingerprints of large-scale neuronal interactions. Nat. Rev. Neurosci. 13, 121-134.

Sirota, A., Montgomery, S., Fujisawa, S., Isomura, Y., Zugaro, M., and Buzsaki, G. (2008). Entrainment of neocortical neurons and gamma oscillations by the hippocampal theta rhythm. Neuron 60 683-697.

Stamatakis, E. A., Marslen-Wilson, W. D., Tyler, L. K., and Fletcher, P. C. (2005). Cingulate control of frontotemporal integration reflects linguistic demands: a three-way interaction in functional connectivity. Neuroimage 28, 115-121.

Steinvorth, S., Wang, C., Ulbert, I., Schomer, D., and Halgren, E. (2010). Human entorhinal gamma and theta oscillations selective for remote autobiographical memory. Hippocampus 20, 166-173.

Sullivan, E. V., Rosenbloom, M. J., and Pfefferbaum, A. (2000). Pattern of motor and cognitive deficits in detoxified alcoholic men. Alcohol. Clin. Exp. Res. 24, 611-621.

Tarter, R. E., Mcbride, H., Buonpane, N. and Schneider, D. U. (1977). Differentiation of alcoholics. Childhood history of minimal brain dysfunction, family history, and drinking pattern. Arch. Gen. Psychiatry 34, 761-768.

Thompson-Schill, S. L., D'esposito, M., Aguirre, G. K., and Farah, M. J. (1997). Role of left inferior prefrontal cortex in retrieval of semantic knowledge: a reevaluation. Proc. Natl. Acad. Sci. U.S.A. 94 14792-14797.

Tracy, J. I., and Bates, M. E. (1999) The selective effects of alcohol on automatic and effortful memory processes. Neuropsychology 13, 282-290.

Van Petten, C., and Luka, B. J. (2006). Neural localization of semantic context effects in electromagnetic and hemodynamic studies. Brain Lang. 97, 279-293.

Vartiainen, J., Liljestrom, M., Koskinen, M., Renvall, H., and Salmelin, R. (2011). Functional magnetic resonance imaging blood oxygenation level-dependent signal and magnetoencephalography evoked responses yield different neural functionality in reading. J. Neurosci. 31, 1048-1058.

Wagner, A. D., Pare-Blagoev, E. J., Clark, J., and Poldrack, R. A. (2001). Recovering meaning: left prefrontal cortex guides controlled semantic retrieval. Neuron 31, 329-338.

Wendt, P. E., and Risberg, J. (2001). Ethanol reduces rCFB activation of left dorsolateral prefrontal cortex during a verbal fluency task. Brain Lang. 77, 197-215.

Wydell, T. N., Vuorinen, T., Helenius, P., and Salmelin, R. (2003). Neural correlates of letter-string length and lexicality during reading in a regular orthography. J. Cogn. Neurosci. 15, 1052-1062.

Zuckerman, M. (1971). Dimensions of sensation seeking. J. Consult. Clin. Psychol. 36, 45-52.

Conflict of Interest Statement: The authors declare that the research was conducted in the absence of any commercial or financial relationships that could be construed as a potential conflict of interest.

Received: 08 February 2012; accepted: 04 April 2012; published online: 24 April 2012.

Citation: Marinkovic K, Rosen BQ, Cox $B$ and Kovacevic S (2012) Event-related theta power during lexical-semantic retrieval and decision conflict is modulated by alcohol intoxication: anatomically constrained MEG. Front. Psychology 3:121. doi: 10.3389/fpsyg.2012.00121

This article was submitted to Frontiers in Language Sciences, a specialty of Frontiers in Psychology.

Copyright (c) 2012 Marinkovic, Rosen, Cox and Kovacevic. This is an openaccess article distributed under the terms of the Creative Commons Attribution Non Commercial License, which permits non-commercial use, distribution, and reproduction in other forums, provided the original authors and source are credited. 